Check for updates

Cite this: RSC Adv., 2020, 10, 33378

\title{
An overview of phytochemicals and potential health-promoting properties of black walnut
}

\begin{abstract}
Danh C. Vu, (D) *a Trang H. D. Nguyen ${ }^{\mathrm{b}}$ and Thi L. Hoc
Black walnut (Juglans nigra L.) is one of the most widely consumed nuts in the United States. The nut has been recognized for its unique, bold flavor, and used as a versatile food ingredient. The objective of this review is to summarize available research data pertaining to phytochemicals present in black walnut and their previously reported health-promoting properties. Black walnut is rich in phenolics and contains higher levels of phytosterols, unsaturated fatty acids and tocopherols than many other commonly consumed nuts. Dietary intervention of these constituents has been associated with a great number of disease-preventive properties. Black walnut has a potential to inhibit the release of proinflammatory mediators in vitro. Similarities in contents of unsaturated fatty acids and tocopherols between black walnut and English walnut suggest that black walnut consumption may produce beneficial effects on cardiovascular disease risks. In addition, the high level of $\gamma$-tocopherol in black walnut could make the nut a cancer-preventive option. Although evidence has shown black walnut kernel is a rich source of phytochemicals of potential importance to human health, there is a paucity of in vitro and in vivo studies on the bioactivities of these phytochemicals isolated from black walnut and the health-promoting properties of black walnut consumption. Clinical studies are needed to better understand the health benefits of black walnut.
\end{abstract}

Received 30th June 2020

Accepted 25th August 2020

DOI: 10.1039/d0ra05714b

rsc.li/rsc-advances
Compared to English walnut or Persian walnut (Juglans regia L.), black walnut has a sweeter, mustier, more complex flavor, making it a versatile ingredient for candies, baked goods and ice cream. ${ }^{4}$ Nutritionally, black walnut is an excellent source of vitamins (folic acid, vitamin B5, vitamin B6, tocopherols), minerals (phosphorus, manganese, magnesium, zinc, potassium), omega-3 fatty acids, and phytochemicals. ${ }^{5}$ Consumption of black walnut may exert a beneficial effect on human vascular function. ${ }^{6}$ Derivatives of black walnut kernels, husk, bark and leaves are thought to have a variety of medicinal properties. For example, a tincture of the nuts, green husk, and leaves is traditionally used in folk medicine as a treatment for biliary and cramp colic, and in removal of intestinal worms. ${ }^{7}$ Dated back in late 1960s, extracts of black walnut leaves and husk were reported to exhibit an antitumor activity in a mouse study. ${ }^{8}$ Recently, evidence has indicated that black walnut kernel extracts possess great potentials to suppress the proinflammatory cytokine production in LPS-induced human promonocytic cell line U-937. ${ }^{9}$ In addition, black walnut kernel extracts have shown inhibitory effects on the growth of bacteria including Staphylococcus aureus. ${ }^{\mathbf{1 0 , 1 1}}$ It is proposed that these bioactivities are attributed to the presence of phytochemical constituents in black walnut. While some researchers relied on traditional fractionation of black walnut extracts to isolate and characterize bioactive components others have taken advantage of advanced computational algorithms and freely available metabolite databases to tentatively identify compounds
${ }^{a}$ Faculty of Technology, Van Lang University, Ho Chi Minh City, Vietnam. E-mail: danh.vc@vlu.edu.vn;dcvgwc@mail.missouri.edu

${ }^{b}$ Institute of Biotechnology and Food Technology, Industrial University of Ho Chi Minh City, Vietnam

${ }^{c}$ Cuu Long Delta Rice Research Institute, Can Tho, Vietnam 


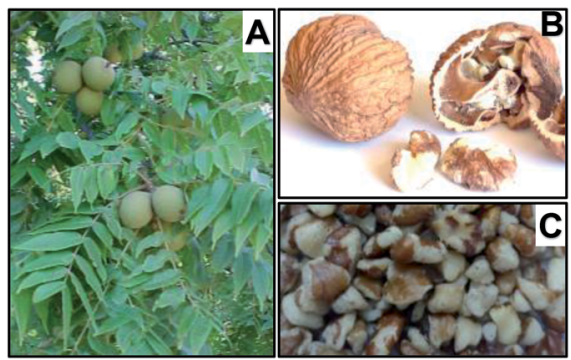

Fig. 1 Black walnut fruits (A), nutshell (B) and kernel (C).

associated with the bioactivities. ${ }^{\mathbf{8 , 9 , 1 1 , 1 2}}$ The purpose of this review is to provide a summary of available information about phytochemicals in black walnut kernel and their potential health-promoting properties. We have also highlighted similarities in phytochemical contents between black walnut and English walnut as well as the recent reports on benefits of English walnut consumption to comment on potential health effects of black walnut.

\section{Bioactive compounds of potential importance to human health}

\subsection{Phenolics}

Phenolics are a diverse class of compounds containing one or more aromatic rings attached directly to hydroxyl groups. These compounds can be classified into subclasses, such as phenolic acids, flavonoids, stilbenes, coumarins, and tannins based on variations in the structural arrangement of aromatic rings and positions of the attached hydroxyl groups. These phenolics have received tremendous attention due to their potentials to positively impact upon human health. One study by Negi et al. (2011) suggests that antioxidant activity of walnut extracts is positively correlated with phenolic content in walnuts. ${ }^{13}$ Recent investigations have shown that black walnut contains a complex mixture of phenolic acids, flavonoids, ellagitannins, gallotannins. 11,12,14 Compared to English walnut, black walnut contains similar levels of most of phenolics that have been reported. For example, levels of ellagic acid, phenolic acids and quercetin glycosides in kernels of the two walnuts are not significantly different. In contrast, catechins, trigalloylglucose, pentagalloylglucose are rarely found to be present in black walnut. There is evidence to suggest that phenolic contents in black walnut may be affected by environmental and climatic conditions. ${ }^{15,16}$ While agronomic practices and geographic factor contribute to changes in phenolic composition of English walnut, it remains unclear how these factors affect that of black walnut. This section is to summarize phenolics recently identified in black walnut kernels and their prominent bioactivities (Table 1).

2.1.1. Phenolic acids. Research has provided a wealth of evidence that indicates links between consumption of diets rich in nuts and maintenance of health and disease prevention. ${ }^{\mathbf{1 7}, 18}$ Along with the many oil nuts, black walnut contains high levels of phenolic acids. ${ }^{12}$ Among the phenolic acids in black walnut, chlorogenic acid (CGA) and its isomer neochlorogenic acid (also known as caffeoylquinic acids) have drawn great attention due to their broad spectrum of potential health benefits. CGA possesses a great potential to attenuate oxidative stress by scavenging free radicals, contributing to metal chelation, mitigating lipid peroxidation and suppressing activity of NADPH oxidase. ${ }^{19}$ A study by Rani et al. (2018) indicates that CGA exerts a beneficial effect against hyperglycemia through its inhibition of ROS generation and amelioration of GPx activity and GSH content. ${ }^{20}$ CGA in extracts of Juglans regia (English walnut) reportedly play an important role in regulation of the selfrenewal ability of colon cancer stem cells (CD133 ${ }^{+} \mathrm{CD} 44^{+}$HCT116). ${ }^{21}$ Similar to CGA, the other phenolic acids in black walnut, including ferulic, $p$-coumaric, $p$-hydroxybenzoic, syringic and vanillic acids, are also of special interest because of their bioactivities potentially important to human health. Some of these, such as syringic and vanillic acids, reportedly contribute to antioxidant activities of black walnut and English walnut extracts. ${ }^{22,23}$ Other phenolic acids, such as ferulic, $p$-coumaric and $p$-hydroxybenzoic acids, may exert powerful actions on glucose metabolism. For example, $p$-coumaric acid was demonstrated to reduce blood glucose elevation in Wistar rats. ${ }^{24}$ The oral administration with $p$-coumaric acid (100 $\mathrm{mg}$ per $\mathrm{kg}$ b.w.) to the male rats injected with streptozotocin (40 mg per $\mathrm{kg}$ b.w.) for 30 days to induce diabetes mellitus significantly reduced blood glucose elevation, levels of total cholesterol and triglycerides in liver and kidney, LDL-C, VLDL-C and increased HDL-C. The authors revealed that the antidiabetic effect involved in pancreatic GLUT-2 activation, protecting pancreatic $\beta$-cells of diabetic rats. In a rat model, $p$-hydroxybenzoic acid was shown to have a potential to produce a hypoglycemic effect in streptozotocin-induced diabetic rats. ${ }^{25}$ Ferulic acid, a hydroxycinnamic acid, exhibited inhibitory effects on body weight gain, body and liver fat accumulation, blood glucose dysregulation and inflammation in Wistar rats and C57BL/6J mice fed with high fat diet. ${ }^{26,27}$ This acid (1000 mg daily for six weeks) is also capable of improving lipid profile, reducing oxidative stress biomarker (MDA) and inflammatory markers (hs-CRP and TNF- $\alpha$ ) in hyperlipidemic subjects. ${ }^{28}$ Gallic acid, also known as 3,4,5-trihydroxybenzoic acid, is found to be present in the kernels of black walnut cultivars with concentrations ranging from 0.5 to $4.3 \mu \mathrm{g} \mathrm{g}^{-1}$. It was also detected in English walnut varieties at slightly higher levels. ${ }^{29}$ This phenolic acid reportedly contributes to antioxidant activities of black walnut. ${ }^{23}$ The antioxidant ability of gallic acid has aroused considerable attention, giving rise to its hepatoprotective effect. For example, gallic acid is effective at attenuating fluoxetine-induced liver damage due to its free radical scavenging potential and TNF- $\alpha$ related antiinflammatory effect. ${ }^{30}$ Gallic acid at a concentration of $6.25 \mu \mathrm{g}$ $\mathrm{mL}^{-1}$ improved glucose uptake by $19.2 \%$ in insulin-resistant FL83B mouse hepatocytes. ${ }^{31}$ In addition, the authors showed gallic acid administration (10 or $30 \mathrm{mg}$ per $\mathrm{kg}$ b.w.) for 4 weeks alleviated hyperglycemia and ameliorated hepatic glucose metabolism in HFD-induced diabetic rats. This demonstrates gallic acid possesses a great potential to prevent diabetes mellitus. 
Table 1 Summary of phenolics identified in black walnut and their bioactivities potentially important to human health

\begin{tabular}{|c|c|c|c|c|c|}
\hline Phenolics & Class & $\begin{array}{l}\text { Concentrations }^{a}(\mu \mathrm{g} \\
\text { per } g \text { of kernel) }\end{array}$ & Effects & Mechanism of action & References \\
\hline \multirow[t]{2}{*}{ Chlorogenic acid } & $\begin{array}{l}\text { Phenolic } \\
\text { acid }\end{array}$ & 1.1 & Antihyperglycemic activity & $\begin{array}{l}\text { Inhibition of ROS } \\
\uparrow \text { GPx activity and GSH }\end{array}$ & 20 \\
\hline & & & Suppression of colon cancer & $\begin{array}{l}\downarrow \text { Expression of CD133, CD } 44, \text { DLK1, and } \\
\text { Notch1 } \\
\text { Blockage of } \beta \text {-catenin/p-GSK3 } \beta \text { signaling } \\
\text { pathway }\end{array}$ & 21 \\
\hline $\begin{array}{l}\text { Neochlorogenic } \\
\text { acid }\end{array}$ & $\begin{array}{l}\text { Phenolic } \\
\text { acid }\end{array}$ & 2.2 & & & \\
\hline$p$-Coumaric acid & $\begin{array}{l}\text { Phenolic } \\
\text { acid }\end{array}$ & $<0.3$ & $\begin{array}{l}\text { Antidiabetic activity } \\
\text { Cholesterol-lowering effect }\end{array}$ & Activation of pancreatic GLUT-2 & 24 \\
\hline $\begin{array}{l}p- \\
\text { Hydroxybenzoic } \\
\text { acid }\end{array}$ & $\begin{array}{l}\text { Phenolic } \\
\text { acid }\end{array}$ & $<1.4$ & Hypoglycemic effect & & 25 \\
\hline \multirow[t]{2}{*}{ Ferulic acid } & $\begin{array}{l}\text { Phenolic } \\
\text { acid }\end{array}$ & $<4.9$ & $\begin{array}{l}\text { Antiobesity, anti-inflammatory, } \\
\text { and antioxidant effects }\end{array}$ & & 26 and 27 \\
\hline & & & $\begin{array}{l}\text { Reduced risk of cardiovascular } \\
\text { disease }\end{array}$ & $\begin{array}{l}\text { Improving lipid profile } \\
\downarrow \text { Oxidative stress biomarker (MDA) } \\
\downarrow \text { Inflammatory markers (hs-CRP and TNF- } \\
\text { ๙) }\end{array}$ & 28 \\
\hline \multirow[t]{2}{*}{ Gallic acid } & $\begin{array}{l}\text { Phenolic } \\
\text { acid }\end{array}$ & $<4.3$ & Hepatoprotective effect & $\begin{array}{l}\downarrow \text { TNF- } \alpha \text { expression } \\
\uparrow \text { Hepatic CAT, SOD activities }\end{array}$ & 29 \\
\hline & & & Antidiabetic activity & & 30 \\
\hline Quinic acid & - & $1.1-7.8$ & & & \\
\hline Syringic acid & $\begin{array}{l}\text { Phenolic } \\
\text { acid }\end{array}$ & $<14.3$ & Antioxidant & & 22 \\
\hline Vanillic acid & $\begin{array}{l}\text { Phenolic } \\
\text { acid }\end{array}$ & $<9.9$ & Antioxidant & & 23 \\
\hline \multirow[t]{2}{*}{ Catechin } & Flavonoid & $<0.6$ & Synergistic anticancer effect & $\begin{array}{l}\downarrow \text { Tumor protein expressions of mTOR and } \\
\text { EGFR } \\
\text { Activation of GADD153-DR5-TRAIL } \\
\text { apoptotic pathway } \\
\uparrow \text { Accumulation of antibiotics in bacterial } \\
\text { cells }\end{array}$ & 32 \\
\hline & & & Suppression of colon cancer & $\begin{array}{l}\downarrow \text { Expression of CD133, CD44, DLK1, and } \\
\text { Notch1 } \\
\text { Blockage of } \beta \text {-catenin/p-GSK3 } \beta \text { signaling } \\
\text { pathway }\end{array}$ & 21 \\
\hline $\begin{array}{l}\text { Epicatechin } \\
\text { gallate }\end{array}$ & Flavonoid & $<13.2$ & & & \\
\hline $\begin{array}{l}\text { Eriodictyol-7-O- } \\
\text { glucoside }\end{array}$ & Flavonoid & $\mathrm{n} / \mathrm{a}$ & Antibacterial activity & & 11 \\
\hline Naringin & Flavonoid & $<1.3$ & Neuroprotective effect & $\begin{array}{l}\uparrow \text { GSH, CAT, SOD activities } \\
\downarrow \text { Production of TNF- } \alpha \\
\text { PI-3K/Akt-dependent Nrf2 activation }\end{array}$ & 35 \\
\hline $\begin{array}{l}\text { Quercetin-3- } \beta \text {-D- } \\
\text { glucoside }\end{array}$ & Flavonoid & $<4.1$ & $\begin{array}{l}\text { Neuroprotective effect in ischemic } \\
\text { stroke }\end{array}$ & $\begin{array}{l}\downarrow \text { TLR4- and NF- } \kappa \text { B-associated productions } \\
\text { of TNF- } \alpha \text {, IL- } 6 \text {, and IL-1 } \beta \\
\text { Deactivation of phosphorylation of ERK, } \\
\text { JNK, MAPK, CREB } \\
\text { Regulation of Bax, Bcl-2, and caspase-3 }\end{array}$ & 37 \\
\hline $\begin{array}{l}\text { Quercetin-3-O- } \\
\text { arabinoside }\end{array}$ & Flavonoid & 0.4 & & & \\
\hline $\begin{array}{l}\text { Quercetin-3-O- } \\
\text { galactoside }\end{array}$ & Flavonoid & 1.4 & $\begin{array}{l}\text { Anti-inflammatory and wound- } \\
\text { healing activities }\end{array}$ & & 38 \\
\hline $\begin{array}{l}\text { Quercetin-3-O- } \\
\text { pentoside }\end{array}$ & Flavonoid & 21.1 & & & \\
\hline $\begin{array}{l}\text { Quercetin-3-O- } \\
\text { rhamnoside }\end{array}$ & Flavonoid & 0.2 & & & \\
\hline Rutin & Flavonoid & $<4.2$ & Hepatoprotective effect & $\begin{array}{l}\uparrow \text { GSH, GPx, GR, CAT activities } \\
\downarrow \text { MDA and NO levels } \\
\downarrow \text { TNF- } \alpha, \text { IL- } 6 \\
\downarrow \text { Expressions of p38-MAPK, NF- } \kappa \text { B, iNOS } \\
\text { and COX- } 2\end{array}$ & 34 \\
\hline
\end{tabular}


Table 1 (Contd.)

\begin{tabular}{|c|c|c|c|c|c|}
\hline Phenolics & Class & $\begin{array}{l}\text { Concentrations }{ }^{a}(\mu \mathrm{g} \\
\text { per } g \text { of kernel) }\end{array}$ & Effects & Mechanism of action & References \\
\hline Ellagic acid & $\begin{array}{l}\text { Phenolic } \\
\text { acid }\end{array}$ & $9.1-72.1$ & Antiatherogenic activity & \multirow{3}{*}{\multicolumn{2}{|c|}{$\begin{array}{l}\downarrow \text { TNF- } \alpha \text {-induced endothelial expression of } 41 \\
\text { VCAM- } 1 \text { and ICAM- } 1\end{array}$}} \\
\hline $\begin{array}{l}\text { 1,3,6-Trigalloyl } \\
\text { glucose }\end{array}$ & Gallotannin & $<11.4$ & & & \\
\hline $\begin{array}{l}\text { Penta- } O \text {-galloyl- } \\
\beta \text {-D-glucose }\end{array}$ & Gallotannin & $<15.2$ & & & \\
\hline Tellimagrandin I & Ellagitannin & $\mathrm{n} / \mathrm{a}$ & Antioxidant activity & & 23 \\
\hline Heterophylliin E & Ellagitannin & $\mathrm{n} / \mathrm{a}$ & Antioxidant activity & & 23 \\
\hline \multirow[t]{3}{*}{ Glansreginin A } & - & $\mathrm{n} / \mathrm{a}$ & Antibacterial activity & & 11 \\
\hline & & & Antioxidant activity & & 29 \\
\hline & & & Anti-inflammatory activity & & 44 \\
\hline
\end{tabular}

${ }^{a}$ Concentration values of phenolic reported in ref. 11, 12, 14 and 23. n/a: the compound was previously tentatively identified, and not quantified.

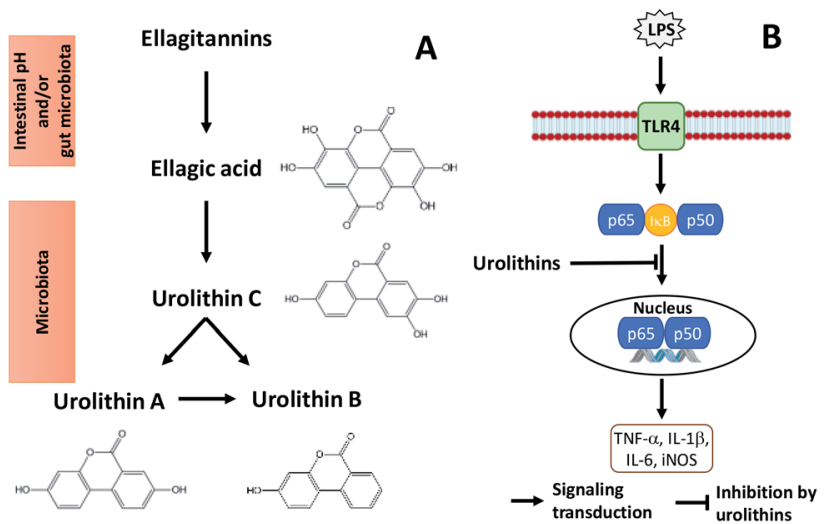

Fig. 2 Metabolism of ellagitannins (A) and a mechanism by which microflora human metabolites of ellagitannins and ellagic acid inhibit LPS-induced inflammation in RAW 264.7 murine macrophages (B).

2.1.2. Flavonoids. Flavonoids have been identified as one of the most common phenolic groups in tree nuts. Catechin and epicatechin gallate belong to the flavan-3-ol group under the flavonoid subclass. Catechin levels were found approximately 100-fold lower in black walnut than in English walnut. ${ }^{12}$ This could be due to catechin mostly existing in the forms of glycosides and gallic acid conjugates in black walnut. Catechin has attracted considerable attention due to its ability against certain cancers. Recent evidence has indicated that catechin and its naturally occurring derivatives act synergistically with anticancer agents, resulting in substantial improvement in growth suppression and apoptosis of breast, colorectal, lung, and prostate cancer cells. ${ }^{32,33}$ Along with other phenolics in walnut extracts, catechin reportedly contributes to regulation of the self-renewal ability of colon cancer stem cells (CD133 $\left.{ }^{+} \mathrm{CD} 44^{+} \mathrm{HCT} 116\right) .{ }^{21}$ Eriodictyol-7-O-glucoside was tentatively identified in black walnut using accurate mass measurements and mass fragmentation data. It is suggested that the compound may contribute to antibacterial activities of black walnut extracts. ${ }^{\mathbf{1 1}}$ Naringin is a flavanone-7-O-glycoside found in walnuts and many other oil nuts. Recent studies have shown that naringin is capable of protecting vulnerable neurons and improving the function of existing neuronal structures. ${ }^{35,36}$ These neuroprotective benefits are mediated by interactions of naringin with cellular signaling cascades in the brain, leading to improvement of antioxidant defense, inhibition of neurotoxin-induced apoptosis, and promotion of neuronal survival. Quercetin-3- $\beta$-D-glucoside, a quercetin glycoside identified in black walnut and English walnut, has been reported to possess a great potential to ameliorate cerebral impairment induced by ischemic stroke. ${ }^{37}$ These in vitro and in vivo studies have indicated that treatment with quercetin-3- $\beta$-D-glucoside reduced the infarct size, apoptosis, oxidative stress, and inflammatory response triggered by ischemia and reperfusion injury. Rutin, also known as quercetin-3-O-rutinoside and identified in different black walnut cultivars, is believed to exhibit multiple bioactivities potentially beneficial to human health, including antioxidative, anti-inflammatory, antidiabetic, anti-adipogenic, hepatoprotective, and neuroprotective properties. For example, pretreatment with rutin (50 and $100 \mathrm{mg}$ per $\mathrm{kg}$ b.w.) alleviated cyclophosphamide-induced hepatotoxicity in Wistar rats due to its ability to diminish oxidative stress and inflammatory responses through targeting MAPK, NF- $\kappa$ B, COX-2, iNOS, COX-2, TNF- $\alpha$, and IL-6. ${ }^{34}$ Quercetin glycosides, including quercetin-3-O-arabinoside, quercetin-3-O-galactoside, quercetin-3-pentoside and quercetin-3-Orhamnoside, were among the flavonoids identified in black walnut extracts. These compounds may exert anti-inflammatory and wound healing actions. ${ }^{38}$

2.1.3. Hydrolyzable tannins. Black walnut has been shown to contain compounds belonging to the hydrolyzable tannin group, such as ellagitannins and gallotannins. Two gallotannins present in black walnut are 1,3,6-trigalloylglucose and penta- $O$-galloyl- $\beta$-D-glucose. ${ }^{12}$ Several compounds of the ellagitannin class, including pedunculagin, tellimagrandin I and heterophylliin E, were tentatively identified in black walnut. ${ }^{23}$ Ellagitannins are hydrolyzed to ellagic acid during digestion, and ellagic acid is then gradually metabolized by intestinal 
Table 2 Summary of phytosterols detected in black walnut and their potential health-promoting properties

\begin{tabular}{|c|c|c|c|c|}
\hline Phytosterols & $\begin{array}{l}\text { Concentration range }{ }^{a} \text { ( } \mu \mathrm{g} \text { per } \mathrm{g} \text { of } \\
\text { kernel) }\end{array}$ & Effects & Mechanism & References \\
\hline \multirow[t]{3}{*}{$\beta$-Sitosterol } & $988.3-1223.9$ & Cholesterol-lowering effect & $\begin{array}{l}\downarrow \text { Intestinal cholesterol binding to } \\
\text { mixed micelles }\end{array}$ & 49 and 52 \\
\hline & & Antioxidant activity & $\begin{array}{l}\uparrow \text { SOD, GPx } \\
\downarrow \text { Catalase }\end{array}$ & 50 \\
\hline & & Anti-inflammatory activity & $\downarrow$ TNF- $\alpha$, IL-6 & 51 \\
\hline Stigmasterol & $<4.0$ & $\begin{array}{l}\text { Antiproliferative effect on colon } \\
\text { cancer cells }\end{array}$ & Stimulation of apoptosis & 53 \\
\hline Campestanol & 26.0 & Cholesterol-lowering effect & $\begin{array}{l}\downarrow \text { Intestinal cholesterol binding to } \\
\text { mixed micelles }\end{array}$ & 49 and 52 \\
\hline Stigmastanol & $12.3-21.5$ & & & \\
\hline Clerosterol & $59.3-88.2$ & $\begin{array}{l}\text { Cytotoxic effects on human } \\
\text { melanoma cells }\end{array}$ & & 54 \\
\hline Cycloeucalenol & $<7.6$ & & & \\
\hline $24-$ & $2.4-52.9$ & & & \\
\hline \multicolumn{5}{|c|}{ Methylenecycloartenol } \\
\hline Citrostadienol & $5.5-12.8$ & Antitumor effect on melanoma cells & & 57 \\
\hline$\Delta^{5,23}$-Stigmastadienol & $4.7-12.3$ & & & \\
\hline$\Delta^{5,24(25)_{-}^{\circ}}$ & $19.4-43.7$ & & & \\
\hline Stigmastadienol & & & & \\
\hline 28-Methylobtusifoliol & $<13.6$ & & & \\
\hline
\end{tabular}

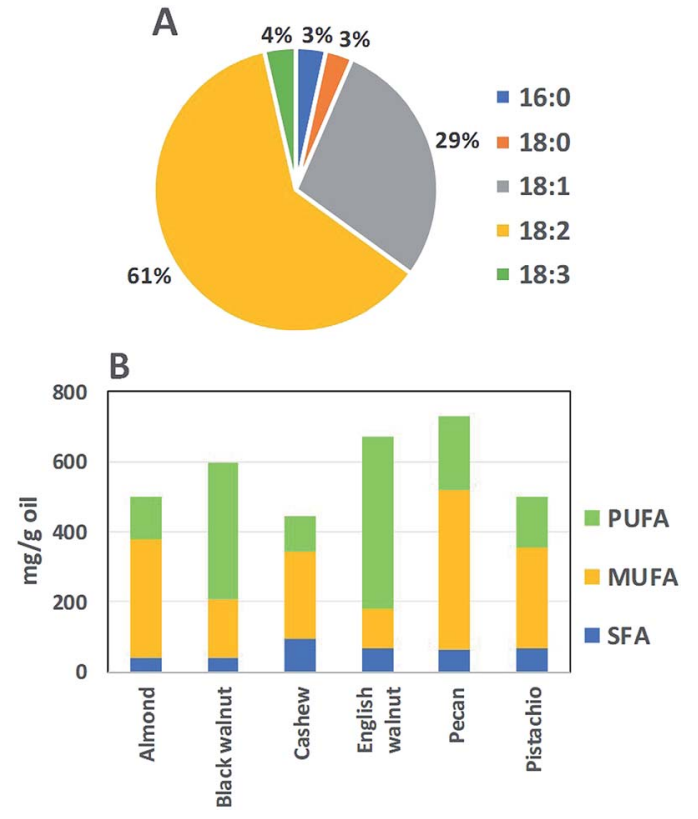

Fig. 3 Fatty acid compositions of black walnut and other edible oil nuts. (A) depicts fatty acid content (\%) in black walnut. (B) presents fatty acid levels in black walnut and other nuts. The data from ref. 58 were used to create the graphs.

microbiota to yield urolithins (Fig. 2A). At physiological concentrations $(\geq 40 \mu \mathrm{M})$, urolithins were reported to inhibit $\mathrm{NF}-\kappa \mathrm{B}$ dependent expression of iNOS and production of pro-

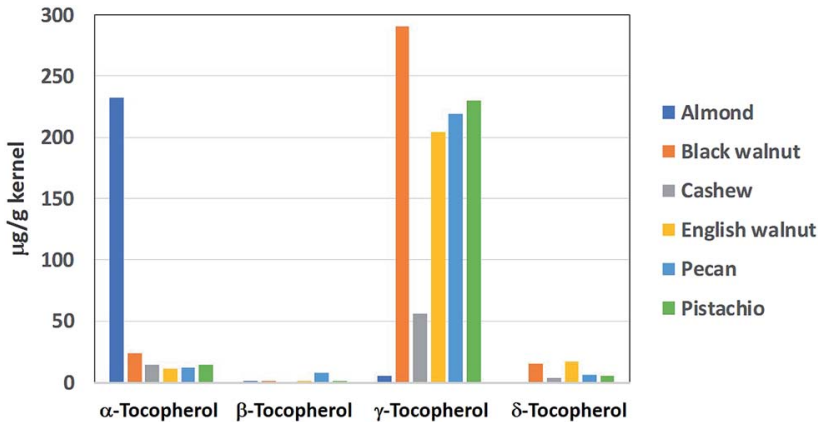

Fig. 4 Tocopherol contents of black walnut and other oil nuts. The bar graph was presented using the data from ref. 58.

inflammatory cytokines (TNF- $\alpha$, IL-1 $\beta$ and IL-6) in RAW 264.7 macrophages (Fig. 2B). ${ }^{39}$ Ellagic acid has been detected in not only black walnut and English walnut but also in Japanese walnut, another Juglans species botanically named Juglans ailanthifolia var. cordiformis. ${ }^{40}$ The concentration of ellagic acid in black walnut was reportedly equivalent to that in English walnut. ${ }^{12}$ Papoutsi et al. (2008) reported that ellagic acid in walnut extracts may exert an antiatherogenic action, suggesting beneficial effects of walnut consumption on cardioprotection. ${ }^{\mathbf{4 1}}$ Ellagic acid is also well known for its antioxidant capacity. The antioxidant ability of ellagic acid has attracted tremendous attention, giving rise to most of its potential health-promoting properties, including anti-inflammatory, antidiabetic effects, 
neuroprotection, hepatoprotection, as well as protection against cardiovascular disease and cancer. ${ }^{42}$ Dietary ellagic acid is metabolized by intestinal microbiota to produce urolithins, which exert multiple bioactivities of potential importance to human health. ${ }^{39,43}$

Glansreginin A, an indicator component in English walnut, was tentatively identified in black walnut based on accurate mass measurements and ion fragmentation data. This compound may be an important contributor to antibacterial activities of black walnut extracts. ${ }^{\mathbf{1 1}}$ Oral administration of walnut glansreginin A at 50-100 mg per kg body weight resulted in a significant suppression of LPS-induced abnormal behavior and LPS-induced activation of microglia in hippocampus in male ICR mice. ${ }^{44}$

\subsection{Phytosterols}

Phytosterols indicate plant-derived compounds with chemical structure highly similar to that of cholesterol. The first investigation into phytosterols in generic black walnut was conducted by Phillips and colleagues in 2005, which included seven identified phytosterols. ${ }^{45}$ Recently, one study has shown that phytosterol contents vary significantly among eleven black walnut cultivars. ${ }^{46}$ The total phytosterol level in black walnut is slightly higher in comparison with English walnut. The use of phytosterols has been touted as being safe and effective in lowering serum cholesterol. The phytosterols marketed as a pharmaceutical drug (cytellin) was first commercialized by Eli Lily in the 1950s. Nowadays, the efficacy of phytosterols as cholesterol-reducing agents has also been demonstrated in the case of phytosterol-supplemented foods. ${ }^{47}$ There is also evidence that phytosterols may contribute to prevention of lifestyle-related diseases such as obesity, diabetes mellitus, hyperlipidemia, and high blood pressure. ${ }^{48}$ This section is to provide a summary of phytosterols previously found to be present in black walnut kernels and their potential health effects (Table 2).

$\beta$-Sitosterol is the most abundant phytosterol in black walnut, with concentrations ranging between 988.3 and 1223.9 $\mu \mathrm{g}$ per $\mathrm{g}$ of kernel. This compound may lower serum cholesterol levels due to its ability to reduce intestinal cholesterol absorption. ${ }^{49}$ This sterol has been reported to alleviate oxidative stress by increasing activities of antioxidant enzymes. ${ }^{50}$ A recent clinical study has revealed an ability of this sterol to prevent obesityrelated chronic inflammation. ${ }^{51}$ These authors have observed negative correlations between serum $\beta$-sitosterol and proinflammatory cytokines (IL-6 and TNF- $\alpha$ ) levels. Along with $\beta$ sitosterol, campesterol and stigmasterol may exert an effect on serum cholesterol levels due to their ability to reduce intestinal cholesterol absorption. ${ }^{49}$ The underlying mechanism by which these phytosterols reduce cholesterol absorption is not entirely understood. It is suggested that they compete with intestinal cholesterol for binding to mixed micelles, resulting in reduced cholesterol uptake in the enterocyte, thereby less cholesterol is incorporated into chylomicrons. ${ }^{52}$ Campesterol and stigmasterol are thought to play an important role with regard to prevention of colon cancer. ${ }^{53}$
Clerosterol is believed to contribute to several cytoprotective activities of the plant extracts. For examples, clerosterol reportedly has cytotoxic effects on human melanoma cells. ${ }^{54}$ Based on the understanding of bioactivities of this sterol, it is proposed that clerosterol-rich food such as black walnut could be used to produce effective preventive and therapeutic agents protecting against UVB-induced skin damages.

Campestanol and stigmastanol are the two phytostanols detected in black walnut. The efficacy of phytostanols in LDLcholesterol reduction has been well documented. Moreover, phytostanols are more effective at reducing LDL-cholesterol compared to phytosterols. ${ }^{49}$

Although $\Delta^{5}$-avenasterol is recognized as a commonly found compound in walnuts and other oil nuts, limited information about its bioactivities is available. It is assumed that this sterol possesses cholesterol-lowering and antioxidant properties. Assessment of potential health promoting activities of $\Delta^{5}$-avenasterol warrants further research.

Other sterols in black walnut, such as cycloartenol, cycloeucalenol and 24-methylenecycloartenol, were reported to have an anti-inflammatory activity against 12-Otetradecanoylphorbol-13-acetate-induced inflammation in mice. ${ }^{55,56}$ A low cytotoxic activity of citrostadienol, a minor sterol in black walnut, at a concentration of $250 \mu \mathrm{g} \mathrm{mL}{ }^{-1}$ was observed in melanoma cell line (B16F10). ${ }^{57}$ Therefore, it is suggested that citrostadienol may have an antitumor activity.

\subsection{Fatty acids}

In black walnut, fatty acids exist in saturated (SFA), monounsaturated (MUFA), and polyunsaturated (PUFA) forms (Fig. 3A and B). The SFA, accounting for about $7 \%$ of the total fatty acids in black walnut oil, comprise palmitic (16:0) and stearic (18:0) acids. The unsaturated fatty acids (MUFA and PUFA) in black walnut oil are similar to those in English walnut oil, consisting of oleic (18:1), linoleic (18:2), and $\alpha$-linolenic (18:3) acids, and making up $93 \%$ of the total fatty acids. Compared to oils of the other edible nuts, black walnut oil contains the lowest amount of SFAs whereas its total level of unsaturated fatty acids is the highest (Fig. 3B).

\subsection{Tocopherols}

Tocopherols are fat-soluble compounds that have been found to possess vitamin $\mathrm{E}$ activity. In black walnut, four different forms or isomers of tocopherols have been identified, namely $\alpha-, \beta-, \gamma-$, and $\delta$-tocopherols. ${ }^{58}$ Among these, $\gamma$-tocopherol is the most abundant form, accounting for approximately $88 \%$ of the total tocopherols ( $330 \mu \mathrm{g}$ per $\mathrm{g}$ of kernel) in black walnut. Compared to the other commonly consumed nuts, black walnut contains the highest level of $\gamma$-tocopherol (Fig. 4). In particular, it has $42 \%$ higher $\gamma$-tocopherol than English walnut. Tocopherols are widely recognized for their potent inhibitory effects on lipid oxidation in foods and biological systems. These compounds are the major lipid-soluble chain-breaking antioxidant in the body, providing defense against lipid peroxidation and protecting cell membranes from free radical assault. ${ }^{59}$ 


\section{Potential health promoting properties}

\subsection{Antioxidant activity}

Nuts of walnut species (Juglans sp.) are valued for constituents possessing high antioxidant activities. For example, extracts of English walnut, Japanese walnut and iron walnut reportedly exhibited high antioxidant activities linked to the presence of phenolics in the nuts. ${ }^{40,60,61}$ As a nut rich in phenolics, black walnut had presumably been able to exhibit antioxidant properties. Indeed, black walnut extracts have recently been shown to exert great antioxidant capacities measured by FRAP assays. ${ }^{23}$ The average FRAP values of black walnut extracts ranged between 452 and $1002 \mathrm{mM} \mathrm{FeCl}_{2}$ per $\mathrm{g}$ walnut. Besides, the antioxidant activities were positively correlated with relative concentrations of thirteen phenolics tentatively identified in the extracts. Among these phenolic compounds, gallic acid, syringic acid, valoneic acid bilactone, epicatechin gallate, tellimagrandin I and pedunculagin had previously been found to contribute to antioxidant properties of English walnut extracts. In addition to FRAP, another method commonly used to assess total antioxidant capacities of walnut extracts is ORAC (oxygen radical absorbance capacity) assay. ${ }^{61,62}$ FRAP has an advantage in quantifying both water- and fat-soluble antioxidants, whereas ORAC is more suitable for evaluating hydrophilic fractions of walnut extracts. For example, a study by Bulló et al. (2010) showed significantly higher ORAC values of hydrophilic fractions than those of lipophilic fractions of walnut-skin extracts and whole walnuts. ${ }^{63}$ While the ORAC assay is among the most recognized methods for assessment of antioxidant capacity of walnuts, it has not been used for black walnut. Based on these findings, it is suggested that ORAC should be assayed on black walnut to give a better understanding of the correlation between antioxidant activity and phenolic composition of the nut.

Research has provided strong evidence that multiple bioactivities of importance to human health arise from antioxidant activity of walnut. For example, English walnut phenolic extracts exhibited protective effects on lungs against oxidative damage caused by toxicants in cigarette smoke in female Wistar rats administered with single dose $(1.3 \mathrm{~mL}$ per $\mathrm{kg}$ b.w. $)$ of cigarette smoke extract through intratracheal instillation. ${ }^{64}$ The effects resulted from significant restoration of glutathione reductase and catalase levels and reduction in xanthine oxidase activity in lung tissue. Extracts of English walnut phenolics (at a dose of $150 \mathrm{mg}$ per $\mathrm{kg}$ b.w.) also reduced lung inflammation by attenuating decreases in activities of glutathione reductase and catalase in lung tissue of Wistar rats intratracheally injected with bleomycin at $10 \mathrm{U}$ per $\mathrm{kg}$ body weight. ${ }^{65}$ While in vitro and in vivo studies on the antioxidative role of English walnut abound in the literature, those of black walnut are limited. Nevertheless, based on the similarities in phenolic content between the two walnuts, it is extrapolated that antioxidant activities of black walnut could give rise to multiple bioactivities potentially important to human health. ${ }^{12}$

\subsection{Antibacterial activity}

Phenolics, such as gallic acid, ellagic acid, ferulic acid and naringin, have been linked to antibacterial actions. ${ }^{66-68}$ It is suggested that the mechanism by which phenolics inhibit bacterial growth includes disruption of membrane structure and/or inhibition of DNA synthesis. ${ }^{69}$ The presence of the phenolic compounds in black walnut hints at possible inhibitory effects of the nut on bacterial growth. Indeed, acetonic extracts of black walnut exhibited antibacterial activity ranging from 125 to $500 \mu \mathrm{g} \mathrm{mL}{ }^{-1}$ while streptomycin fell within 7.8-63 $\mu \mathrm{g} \mathrm{mL}{ }^{-1} .^{10}$ Recently, methanolic extracts of black walnut have been reported to show inhibitory effects on Staphylococcus aureus, with the largest zone of inhibition reaching $12 \mathrm{~mm} .{ }^{11}$ Interestingly, the study revealed the contributions of several phenolics, including glansreginin A, catechin derivatives, quercetin glycosides and eriodictyol-7-O-glucoside, to the antibacterial activity. However, due to a lack of a positive control of a standard antibiotic to compare the activity of the extracts in the study, it remains unclear how potent the antibacterial activity of black walnut is.

\subsection{Anti-inflammatory activity}

A recent study on black walnut has revealed that black walnut extracts have the capacity to suppress the production of six proinflammatory cytokines (TNF- $\alpha$, IL-1 $\beta$, IL-6, IL-8, IL-10 and MCP-1) in PMA-differentiated, LPS-induced human promonocytic cells (U937). ${ }^{9}$ The authors suggest that the inhibitory effects are linked to the presence of several phenolics in black walnut, including gallic acid, quercetin, quercetin glycosides, 3-methylquercetin and ellagitannins. Quercetin and 3methylquercetin $(30 \mathrm{mM})$ were previously reported to exhibit the similar inhibitory effects on production of TNF- $\alpha$, IL- 6 and IL-1 in PMA-differentiated, LPS-stimulated U937 cells. $^{70}$ Evidence shows that ellagic acid and walnut extracts containing this compound as a major phenolic constituent have abilities to decrease bleomycin-induced lung inflammation in male Wistar rats. ${ }^{65,71}$ This has raised a question as to whether phenolic-rich black walnut extracts inherit potential anti-inflammatory properties from their phenolic constituents. While these effects are interesting, it should be noted that cytokine suppressive properties of black walnut extracts could represent additive or synergistic effects of multiple phenolics rather than through specific constituents present in the black walnut. Despite limited information about the ability of black walnut to impact upon inflammation in vivo and in human subjects, it is suggested that black walnut may be beneficial in retarding inflammatory diseases.

\subsection{Antidiabetic activity}

As graphically summarized in Fig. 3B, following English walnut, black walnut contains the second highest levels of linoleic acid, an $\omega-6$ PUFA, among the commonly consumed oil nuts. Prior research has attested to beneficial effects on insulin sensitivity when SFA and trans fatty acids are replaced with unsaturated fatty acids, leading to reduced risks of type 2 diabetes (T2D). ${ }^{72}$ 
Notably, $\omega-6$ PUFA, particularly linoleic acid, play an important role in preventing T2D through their ability to improve insulin sensitivity. ${ }^{72,73}$ While some researchers have suggested that consumption of $\omega-3$ PUFA (0.4-5 g per day, for at least 8 weeks) could be an alternative treatment for $\mathrm{T} 2 \mathrm{D},{ }^{74}$ others have reported unconvincing inverse associations of $\omega-3$ PUFA intake with T2D risks. ${ }^{75}$ Therefore, it is uncertain as to whether $\omega-3$ PUFA have impacts on insulin sensitivity and glycemic control. In a review article on dietary $\omega-3$ PUFA in T2D, Jafari et al. (2013) pointed to genetic factors and lifestyle of participants, as well as variations in dietary patterns that made it difficult to draw a final conclusion of how $\omega$-3 PUFA affect insulin sensitivity. ${ }^{73}$ Thus, future studies are necessary and should be focused on how black walnut consumption and its fatty acids could effectively help combat T2D.

\subsection{Cardioprotective effect}

High blood pressure and high cholesterol are among the key risk factors for cardiovascular diseases (CVD).${ }^{76}$ Prior research has yielded much evidence that multiple health benefits, including lowering of serum LDL and total cholesterol levels as well as significant reduction in diastolic blood pressure are positively influenced by consumption of English walnut. ${ }^{77,78}$ These benefits are in part ascribable to the presence of unsaturated fatty acids and tocopherols. It is important to note that there are similarities in fatty acid and tocopherol compositions between black walnut and English walnut (Fig. 3B and 4). From this point of view, it is possible to infer that black walnut may produce beneficial effects on CVD risks. This section is to comment on how fatty acids and tocopherols are beneficial to CVD.

Remarkable scientific interest has been focused on the impact of unsaturated fatty acids in the development of CVD. Studies have suggested that intake of unsaturated fatty acids, particularly PUFA, has beneficial effects on factors associated with CVD risks. ${ }^{79}$ For example, it is shown that intake of $\omega-3$ and w-6 PUFA, through walnut consumption (43 g per day for 8 weeks) significantly decreases plasma total, LDL, and non-HDL cholesterol levels in normal and mildly hyperlipidemic people, potentially leading to a reduced risk of CVD. ${ }^{80}$ In a review of dietary $\omega-3$ fatty acids and CVD, Mori (2014) concludes that this group of fatty acids is clinically safe at doses up to $4 \mathrm{~g} \mathrm{~d}^{-1}$, and no adverse drug interactions with cholesterol-lowering or antihypertensive medications have been documented. ${ }^{\mathbf{8 1}}$ Evidence has also suggested that PUFA consumption may improve vascular and cardiac hemodynamics, endothelial function, reduce triglycerides, and lower inflammation, thrombosis, and arrhythmia. $^{\mathbf{8 2 , 8 3}}$ The molecular mechanisms by which PUFA positively affect CVD risks include alteration of membrane structure and associated functions, influence on ion channel activities, changes in eicosanoid synthesis, regulation of gene expression through nuclear receptors and transcription factors, and production of PUFA-derived bioactive metabolites. ${ }^{\mathbf{8 2 - 8 4}}$

Along with unsaturated fatty acids, tocopherols have been known to influence cardiovascular health. Antioxidant activity of tocopherols was shown to give rise to preventive effects on cardiovascular diseases. For example, treatment with tocopherol supplement for 8 weeks decreased platelet aggregation, and lipid peroxidation in erythrocytes, and increase activation of endothelial NOS in leukocytes, suggesting beneficial effects of tocopherols on cardiovascular system..$^{85-88}$ Notably, these studies also highlighted that the mixed tocopherols had more potent effects than $\alpha$-tocopherol alone. Mechanistic research has revealed that $\gamma$-tocopherol exhibits distinctive antioxidant and anti-inflammatory properties that are superior to those of $\alpha$ tocopherol in prevention and treatment of chronic diseases. ${ }^{\mathbf{5 9 , 8 9}}$

In summary, as a rich source of MUFA, PUFA and tocopherols, especially the highest level of $\gamma$-tocopherol, similar to English walnut, black walnut may potentially provide protective effects against cardiovascular risks.

\subsection{Anticancer activity}

In a review article commenting on in vivo anticancer properties of walnut phytochemicals, Hardman et al. (2014) concluded $\gamma$ tocopherol played an important role in contributing to anticarcinogenic activity of walnut diet. ${ }^{90} \gamma$-tocopherol also has benefits against prostate and colon cancers via activation of peroxisome proliferator-activated receptors (PPAR) while $\alpha$ tocopherol is not identified as being beneficial in attenuating carcinogenesis. ${ }^{\mathbf{9 1 9 2}}$ At this point, it is extrapolated that the high level of $\gamma$-tocopherol in black walnut could make the nut a cancer-preventive option in a healthy diet.

\section{Distinctive flavors of black walnut}

Fruity aroma is the unique attribute found in black walnut while it is not reported in English walnut. ${ }^{4}$ This is confirmed and reinforced by the detection of many fruity-flavored esters in black walnut by Lee et al. (2011)..$^{93}$ More than $50 \%$ of the total VOCs released from black walnut kernel are esters, with methyl isovalerate preponderating over the other VOCs. This also indicates that aromatic composition of black walnut is significantly different from that of English walnut with high aldehyde content. Esters may play an influential role in the aroma of nuts and fruits. They are biosynthetically formed through the $\beta$ oxidation of fatty acids and/or amino acid metabolism. In addition to esters, alcohols, aldehydes and ketones are among the VOCs released from black walnut kernel. ${ }^{93}$ Aldehydes are the products of oxidative decomposition of linoleic and linolenic acids. As summarized earlier, black walnut is rich in linoleic and linolenic acids (33 and $2 \mathrm{~g}$ per $100 \mathrm{~g}$ of kernel, respectively), which may account for the presence of aldehydes in the black walnut volatile profile. Levels of esters decrease from light to dark black walnut kernel, while those of alcohols, aldehydes and ketones, conversely, have a positive correlation with kernel color. Delayed harvesting and hulling are able to negatively affect kernel color of black walnut, ${ }^{94}$ which in turn can lead to unpleasant flavors. It is widely accepted that aroma and flavor provide the defining characteristic of how we experience food. Therefore, analyses of volatile constituents linked to flavor have become important, helping understand the nature of existing black walnut, evaluate quality and study shelf-life of the nut. 


\section{Botanical aspects}

Black walnut is a large deciduous tree that can grow to a height of 38 meters, but typically 22-30 meters. Mature trees develop long, smooth trunks and small rounded crowns, often with a few ascending and spreading coarse branches. Black walnut leaves are odd-pinnate compound. A leaf is up to $60 \mathrm{~cm}$ long, consisting of 13-23 oblong to lanceolate leaflets. Monoecious flowers bloom in late spring, and female ones develop into edible nuts enclosed in yellow-green husk. Black walnut fruits have a spherical shape, are about $5 \mathrm{~cm}$ in diameter, and occur singly or in groups of 2-3. Each fruit contains a dark brown hard-shelled nut. Black walnut is found generally growing throughout the central and eastern parts of the United States. The range of this species extends from Kansas to the North Carolina coast, from Minnesota to Texas, and from Massachusetts and Connecticut to Northern Florida. ${ }^{95}$

\section{Production and applications of black walnut}

Black walnut has a bold, unique flavor which has been a staple of many sweet and savory recipes in American Midwest kitchens. ${ }^{4}$ This versatile nut is widely used as a food ingredient, supplementing a rich taste and texture to baked goods, ice cream and confections. ${ }^{\mathbf{9 6}, 97}$ Along with nutmeat, black walnut shell has been marketed and sold globally since 1950s. The shell, is among the hardest part of the whole nut, serves as a highly useful product for a wide array of applications. After the nutmeat is removed, the shell is crushed, ground into different standard mesh sizes for industrial uses. As a natural, biodegradable, durable material with excellent strength characteristics, the black walnut shell is an abrasive media used for blast cleaning and tumbling, polishing, and cosmetics. A variety of cosmetics and soaps often contain nutshell for its abrasive action. In oil industry, the shell is used as an important ingredient in making and maintaining seals in fracture zones, and as an environmentally safe and effective filter media separating crude oil from water. Recently, the shell has been discovered as a revolutionary, environmentally-sound new artificial media for sports turf, replacing traditional crumb rubber turf made from old shredded tires.

Black walnut is also known as one of the North America's most prized hardwood tree species for timber production. Black walnut high-quality wood is used for furniture, cabinet-work, flooring, gunstocks, and other decorative interior applications.

\section{Future research and conclusions}

Black walnut is among the commonly consumed nuts in the United States. The above summary of data available in the literature is focused on the major classes of black walnut phytochemicals including phenolics, phytosterols, fatty acids, and tocopherols. The summary also highlights similarities in phytochemical contents between black walnut and English walnut. Black walnut contains greater levels of total phytosterols, unsaturated fatty acids, and tocopherols compared to many other nuts. Several studies showed that black walnut extracts had antibacterial and antioxidant activities, as well as great potentials to inhibit proinflammatory mediator release in vitro. In view of benefits to human health resulting from dietary intervention of the phytochemicals present in black walnut, it is concluded that these compounds possess numerous disease-preventive properties. Although there is a paucity of research into disease prevention of black walnut, based on the aforementioned data, it is presumed that regular black walnut consumption could contribute to protection against the development of many lifestyle-related diseases, age-related neurodegenerative disorders, and even certain types of cancer. Future research and clinical studies should be focused on a better understanding of the health promotion of black walnut and its isolated bioactive compounds.

\section{Abbreviations}

$\begin{array}{ll}\text { b.w. } & \text { Body weight } \\ \text { LPS } & \text { Lipopolysaccharide } \\ \text { TNF- } \alpha & \text { Tumor necrosis factor } \alpha \\ \text { NF- } \kappa \text { B } & \text { Nuclear factor } \kappa \text { B } \\ \text { IC50 } & \text { Half-maximal inhibitory concentration } \\ \text { HBV } & \text { Hepatitis B virus } \\ \text { HBsAg } & \text { Hepatitis B surface antigen } \\ \text { IFN- } \gamma & \text { Interferon- } \gamma \\ \text { IL-6 } & \text { Interleukin } 6 \\ \text { TLR4 } & \text { Toll-like receptor } 4 \\ \text { IL-1 } \beta & \text { Interleukin 1 } \beta \\ \text { JNK } & \text { c-Jun N-terminal kinases } \\ \text { ERK } & \text { Extracellular signal-regulated kinases } \\ \text { MAPK } & \text { Mitogen-activated protein kinases } \\ \text { Bcl-2 } & \text { B-cell lymphoma 2 } \\ \text { Bax } & \text { Bcl-2-associated X protein } \\ \text { COX-2 } & \text { Cyclooxygenase 2 } \\ \text { iNOS } & \text { Inducible nitric oxide synthase } \\ \text { LDL } & \text { Low-density lipoprotein } \\ \text { HDL } & \text { High-density lipoprotein } \\ \text { UVB } & \text { Ultraviolet B } \\ \text { PGE2 } & \text { Prostaglandin E2 } \\ \text { VOCs } & \text { Volatile organic compounds } \\ & \end{array}$

\section{Conflicts of interest}

The authors report no conflicts of interest relevant to this article.

\section{References}

1 M. V. Coggeshall, HortScience, 2011, 46, 340-342.

2 Hammons Products Company, Black walnut comes to a successful end: December 21, 2017, https://blackwalnuts.com/press-release/black-walnut-harvest-comes-to-asuccessful-end, accessed August 1, 2020. 
3 Hammons Products Company, Black walnut news. Crop update: December 3, 2019, https://black-walnuts.com/2019/ 12/crop-update-december-3-2019, accessed August 1, 2020.

4 M. R. Warmund, J. Elmore, M. Drake and M. D. Yates, J. Sci. Food Agric., 2009, 89, 117-121.

5 USDA, U.S. Department of Agriculture Nutrient Data Base, http://ndb.nal.usda.gov/ndb/search, accessed May 20, 2019.

6 P. J. Fitschen, K. R. Rolfhus, M. R. Winfrey, B. K. Allen, M. Manzy and M. A. Maher, J. Med. Food, 2011, 14, 890-898.

7 A. R. Hutchens, A Handbook of Native American Herbs: The Pocket Guide to 125 Medicinal Plants and Their Uses, Shambhala Publications, 1992.

8 U. C. Bhargava and B. A. Westfall, J. Pharm. Sci., 1968, 57, 1674-1677.

9 K.-V. Ho, K. L. Schreiber, D. C. Vu, S. M. Rottinghaus, D. E. Jackson, C. R. Brown, Z. Lei, L. W. Sumner, M. V. Coggeshall and C.-H. Lin, Front. Pharmacol., 2019, 10, 1059.

10 R. Amarowicz, G. A. Dykes and R. B. Pegg, Fitoterapia, 2008, 79, 217-219.

11 K.-V. Ho, Z. Lei, L. Sumner, M. Coggeshall, H.-Y. Hsieh, G. Stewart and C.-H. Lin, Metabolites, 2018, 8, 58.

12 D. C. Vu, P. H. Vo, M. V. Coggeshall and C.-H. Lin, J. Agric. Food Chem., 2018, 66, 4503-4511.

13 A. S. Negi, S. Luqman, S. Srivastava, V. Krishna, N. Gupta and M. P. Darokar, Pharm. Biol., 2011, 49, 669-673.

14 J. Rorabaugh, A. Singh, I. Sherrell, M. Freeman, N. Vorsa, P. Fitschen, C. Malone, M. Maher and T. Wilson, Food Nutr. Sci., 2011, 2011(2), 193-200.

15 M. Cohen, C. Valancogne, S. Dayau, T. Ameglio, P. Cruiziat and P. Archer, Acta Hortic., 1996, 273-280.

16 C. Lynch, K. Koppel and W. Reid, J. Food Sci., 2016, 81, S719S727.

17 Y. Bao, J. Han, F. B. Hu, E. L. Giovannucci, M. J. Stampfer, W. C. Willett and C. S. Fuchs, N. Engl. J. Med., 2013, 369, 2001-2011.

18 C. Alasalvar, J.-S. Salvadó and E. Ros, Food Chem., 2020, 314, 126192.

19 N. Tajik, M. Tajik, I. Mack and P. Enck, Eur. J. Nutr., 2017, 56, 2215-2244.

20 M. R. P. Rani, N. Anupama, M. Sreelekshmi and K. G. Raghu, Biomed. Pharmacother., 2018, 100, 467-477.

21 J. Lee, Y.-S. Kim, J. Lee, S. C. Heo, K. L. Lee, S.-W. Choi and Y. Kim, Nutrients, 2016, 8, 439.

22 Z. Zhang, L. Liao, J. Moore, T. Wu and Z. Wang, Food Chem., 2009, 113, 160-165.

23 D. C. Vu, J. Park, K.-V. Ho, L. W. Sumner, Z. Lei, C. M. Greenlief, B. Mooney, M. V. Coggeshall and C.-H. Lin, J. Food Meas. Charact., 2020, 14, 770-777.

24 V. Amalan, N. Vijayakumar, D. Indumathi and A. Ramakrishnan, Biomed. Pharmacother., 2016, 84, 230-236.

25 P. Peungvicha, S. S. Thirawarapan and H. Watanabe, Jpn. J. Pharmacol., 1998, 78, 395-398.

26 N. J. Salazar-López, H. Astiazarán-García, G. A. GonzálezAguilar, G. Loarca-Piña, J.-M. Ezquerra-Brauer, J. A. Domínguez Avila and M. Robles-Sánchez, Nutrients, 2017, 9, 675 .
27 W. Wang, Y. Pan, H. Zhou, L. Wang, X. Chen, G. Song, J. Liu and A. Li, Food Agric. Immunol., 2018, 29, 1116-1125.

28 A. Bumrungpert, S. Lilitchan, S. Tuntipopipat, N. Tirawanchai and S. Komindr, Nutrients, 2018, 10, 713.

29 A. Slatnar, M. Mikulic-Petkovsek, F. Stampar, R. Veberic and

A. Solar, Food Res. Int., 2015, 67, 255-263.

30 O. Karimi-Khouzani, E. Heidarian and S. A. Amini, Pharmacol. Rep., 2017, 69, 830-835.

31 D.-W. Huang, W.-C. Chang, J. S.-B. Wu, R.-W. Shih and S.-C. Shen, Nutr. Res., 2016, 36, 150-160.

32 H. Fujiki, E. Sueoka, T. Watanabe and M. Suganuma, J. Cancer Res. Clin. Oncol., 2015, 141, 1511-1522.

33 E. C. Yiannakopoulou, Pharmacology, 2014, 94, 245-248.

34 S. Nafees, S. Rashid, N. Ali, S. K. Hasan and S. Sultana, Chem.-Biol. Interact., 2015, 231, 98-107.

35 B. Ben-Azu, E. E. Nwoke, A. O. Aderibigbe, I. A. Omogbiya, A. M. Ajayi, E. T. Olonode, S. Umukoro and E. O. Iwalewa, Biomed. Pharmacother., 2019, 109, 536-546.

36 G. Kulasekaran and S. Ganapasam, Mol. Cell. Biochem., 2015, 409, 199-211.

37 C.-P. Wang, Y.-W. Shi, M. Tang, X.-C. Zhang, Y. Gu, X.-M. Liang, Z.-W. Wang and F. Ding, Mol. Neurobiol., 2017, 54, 2126-2142.

38 S. Özbilgin, Ö. B. Acıkara, E. K. Akkol, I. Süntar, H. Keleș and G. S. İșcan, J. Ethnopharmacol., 2018, 224, 400-408.

39 J. P. Piwowarski, A. K. Kiss, S. Granica and T. Moeslinger, Mol. Nutr. Food Res., 2015, 59, 2168-2177.

40 L. Li, R. Tsao, R. Yang, C. Liu, H. Zhu and J. C. Young, J. Agric. Food Chem., 2006, 54, 8033-8040.

41 Z. Papoutsi, E. Kassi, I. Chinou, M. Halabalaki, L. Skaltsounis and P. Moutsatsou, Br. J. Nutr., 2008, 99, 715-722.

42 J.-L. Ríos, R. M. Giner, M. Marín and M. C. Recio, Planta Med., 2018, 84, 1068-1093.

43 C. Sánchez-González, V. Noé and M. Izquierdo-Pulido, Food Funct., 2014, 5, 2922-2930.

44 R. Haramiishi, S. Okuyama, M. Yoshimura, M. Nakajima, Y. Furukawa, H. Ito and Y. Amakura, Biosci., Biotechnol., Biochem., 2019, 1-11.

45 K. M. Phillips, D. M. Ruggio and M. Ashraf-Khorassani, J. Agric. Food fChem., 2005, 53, 9436-9445.

46 D. C. Vu, Z. Lei, L. W. Sumner, M. V. Coggeshall and C.-H. Lin, J. Food Compos. Anal., 2019, 75, 61-69.

47 A. S. Truswell, in Cholesterol and Beyond, Springer, 2010, pp. 125-128.

48 S. Mohamed, Trends Food Sci. Technol., 2014, 35, 114-128.

49 K. Musa-Veloso, T. H. Poon, J. A. Elliot and C. Chung, Prostaglandins, Leukotrienes Essent. Fatty Acids, 2011, 85, 928.

50 M. Vivancos and J. J. Moreno, Free Radicals Biol. Med., 2005, 39, 91-97.

51 M. Kurano, K. Hasegawa, M. Kunimi, M. Hara, Y. Yatomi, T. Teramoto and K. Tsukamoto, Biochim. Biophys. Acta, Mol. Cell Biol. Lipids, 2018, 1863, 191-198.

52 E. D. Smet, R. P. Mensink and J. Plat, Mol. Nutr. Food Res., 2012, 56, 1058-1072. 
53 A. Álvarez-Sala, M. a. Á. Ávila-Gálvez, A. Cilla, R. Barberá, G. Garcia-Llatas, J. C. Espí-n and A. González-Sarrí-as, J. Funct. Foods, 2018, 49, 52-60.

54 A. D. Kim, Y. Lee, S.-H. Kang, G. Y. Kim, H. S. Kim and J. W. Hyun, Mar. Drugs, 2013, 11, 418-430.

55 T. Akihisa, K. Yasukawa, M. Yamaura, M. Ukiya, Y. Kimura, N. Shimizu and K. Arai, J. Agric. Food Chem., 2000, 48, 23132319.

56 P. Y. Mali and S. S. Panchal, Asian Pac. J. Trop. Med., 2017, 10, 430-438.

57 K. B. Oliveira, É. Palú, A. M. Weffort-Santos and B. H. Oliveira, Rev. Bras. Farmacogn., 2013, 23, 249-258.

58 K. S. Robbins, E.-C. Shin, R. L. Shewfelt, R. R. Eitenmiller and R. B. Pegg, J. Agric. Food Chem., 2011, 59, 12083-12092. 59 Q. Jiang, Free Radicals Biol. Med., 2014, 72, 76-90.

60 J. A. Vinson and Y. Cai, Food Funct., 2012, 3, 134-140.

61 P. Gao, R. Liu, Q. Jin and X. Wang, Food Chem., 2019, 279, 279-287.

62 R. Blomhoff, M. H. Carlsen, L. F. Andersen and D. R. Jacobs, Br. J. Nutr., 2006, 96, S52-S60.

63 M. Bulló, M. R. Nogués, P. López-Uriarte, J. Salas-Salvadó and M. Romeu, Nutrition, 2010, 26, 823-828.

64 W. Qamar and S. Sultana, Hum. Exp. Toxicol., 2011, 30, 499506.

65 S. Beigh, H. Rashid, S. Sharma, S. Parvez and S. Raisuddin, Biomed. Pharmacother., 2017, 94, 418-429.

66 A. Borges, C. Ferreira, M. J. Saavedra and M. Simoes, Microb. Drug Resist., 2013, 19, 256-265.

67 B. Özçelik, M. Kartal and I. Orhan, Pharm. Biol., 2011, 49, 396-402.

68 V. W. K. Tsui, R. W. K. Wong and A. B. M. Rabie, Phytother. Res., 2008, 22, 401-406.

69 L. Bouarab-Chibane, V. Forquet, P. Lantéri, Y. Clément, L. Léonard-Akkari, N. Oulahal, P. Degraeve and C. Bordes, Front. Microbiol., 2019, 10, 829.

70 T. Okoko and I. F. Oruambo, Food Chem. Toxicol., 2009, 47, 809-812.

71 S. Khan, S. Parvez, B. Chaudhari, F. Ahmad, S. Anjum and S. Raisuddin, Food Chem. Toxicol., 2013, 58, 210-219.

72 U. Risérus, W. C. Willett and F. B. Hu, Prog. Lipid Res., 2009, 48, 44-51.

73 T. Jafari, A. A. Fallah and L. Azadbakht, Maturitas, 2013, 74, 303-308.

74 O. G. L. Coelho, B. P. da Silva, D. M. U. P. Rocha, L. L. Lopes and R. d. C. G. Alfenas, Crit. Rev. Food Sci. Nutr., 2017, 57, 3614-3619.
75 A. O. Akinkuolie, J. S. Ngwa, J. B. Meigs and L. Djoussé, Clin. Nutr., 2011, 30, 702-707.

76 M. Lutz, E. Fuentes, F. Ávila, M. Alarcón and I. Palomo, Molecules, 2019, 24, 366.

77 M. Domènech, M. Serra-Mir, I. Roth, T. Freitas-Simoes, C. Valls-Pedret, M. Cofán, A. López, A. Sala-Vila, C. Calvo and S. Rajaram, Hypertension, 2019, 73, 1049-1057.

78 A. M. Tindall, K. S. Petersen, A. C. Skulas-Ray, C. K. Richter, D. N. Proctor and P. M. Kris-Etherton, J. Am. Heart Assoc., 2019, 8, e011512.

79 W.-S. Yang, Y.-Y. Chen, P.-C. Chen, H.-C. Hsu, T.-C. Su, H.-J. Lin, M.-F. Chen, Y.-T. Lee and K.-L. Chien, Sci. Rep., 2019, 9, 1-9.

80 C. Bamberger, A. Rossmeier, K. Lechner, L. Wu, E. Waldmann, R. Stark, J. Altenhofer, K. Henze and K. Parhofer, Nutrients, 2017, 9, 1097.

81 T. A. Mori, Proc. Nutr. Soc., 2014, 73, 57-64.

82 D. Mozaffarian and J. H. Y. Wu, J. Am. Coll. Cardiol., 2011, 58, 2047-2067.

83 K. R. Zehr and M. K. Walker, Prostaglandins Other Lipid Mediators, 2018, 134, 131-140.

84 P. C. Calder, J. Nutr., 2012, 142, 592S-599S.

85 M. Liu, R. Wallin and T. Saldeen, Nutr. Res., 2002, 22, 12531263.

86 M. Liu, R. Wallin, A. Wallmon and T. Saldeen, J. Cardiovasc. Pharmacol., 2002, 39, 714-721.

87 M. Liu, A. Wallmon, C. Olsson-Mortlock, R. Wallin and T. Saldeen, Am. J. Clin. Nutr., 2003, 77, 700-706.

88 M. D. Thompson and R. V. Cooney, Nutr. Cancer, 2020, 72, 808-825.

89 P. Mathur, Z. Ding, T. Saldeen and J. L. Mehta, Clin. Cardiol., 2015, 38, 570-576.

90 W. E. Hardman, J. Nutr., 2014, 144, 555S-560S.

91 S. E. Campbell, W. L. Stone, S. G. Whaley, M. Qui and K. Krishnan, BMC Cancer, 2003, 3, 25.

92 S. E. Campbell, P. R. Musich, S. G. Whaley, J. B. Stimmel, L. M. Leesnitzer, S. Dessus-Babus, M. Duffourc, W. Stone, R. A. Newman and P. Yang, Nutr. Cancer, 2009, 61, 649-662.

93 J. Lee, L. Vázquez-Araújo, K. Adhikari, M. Warmund and J. Elmore, J. Food Sci., 2011, 76, C199-C204.

94 M. R. Warmund, HortScience, 2008, 43, 2256-2258.

95 R. D. Williams, Silvics of North America, 1990, vol. 2, pp. 391399.

96 C. Lynch, K. Koppel and W. Reid, Int. J. Food Sci. Technol., 2017, 52, 1594-1603.

97 A. E. Miller and D. H. Chambers, LWT, 2013, 53, 139-145. 